\title{
Significant Atmospheric Boundary Layer Change Observed above an Agulhas Current Warm Cored Eddy
}

\author{
C. Messager ${ }^{1}$ and S. Swart ${ }^{2,3}$ \\ ${ }^{1}$ Laboratoire de Physique des Océans, CNRS, UMR 6523, BP 70, 29280 Plouzané Cedex, France \\ ${ }^{2}$ Southern Ocean Carbon \& Climate Observatory, Council for Scientific \& Industrial Research, 15 Lower Hope Street, \\ Rosebank 7700, South Africa \\ ${ }^{3}$ Department of Oceanography, University of Cape Town, Private Bag X3, Rondebosch 7707, South Africa
}

Correspondence should be addressed to C. Messager; christophe.messager@ifremer.fr

Received 2 December 2015; Accepted 1 February 2016

Academic Editor: Jorge E. Gonzalez

Copyright (C) 2016 C. Messager and S. Swart. This is an open access article distributed under the Creative Commons Attribution License, which permits unrestricted use, distribution, and reproduction in any medium, provided the original work is properly cited.

\begin{abstract}
The air-sea impact of a warm cored eddy ejected from the Agulhas Retroflection region south of Africa was assessed through both ocean and atmospheric profiling measurements during the austral summer. The presence of the eddy causes dramatic atmospheric boundary layer deepening, exceeding what was measured previously over such a feature in the region. This deepening seems mainly due to the turbulent heat flux anomaly above the warm eddy inducing extensive deep and persistent changes in the atmospheric boundary layer thermodynamics. The loss of heat by turbulent processes suggests that this kind of oceanic feature is an important and persistent source of heat for the atmosphere.
\end{abstract}

\section{Introduction}

The Agulhas Current is considered the strongest western boundary current globally. The impact of this current on climate, regional weather, and marine ecosystem has been previously described in Jury [1], Rouault and Lutjeharms [2], and Lutjeharms [3]. This powerful current produces meanders, which eject many persistent eddies in the Agulhas Retroflection and Cape Basin regions. Some eddies translate westward into the south Atlantic Ocean $[4,5]$, while others remain in the vicinity of the Agulhas Retroflection before moving eastward or being reabsorbed by the Agulhas Return Current [3]. These eddies are numerous in this region. For instance, 102 Agulhas Rings were detected and tracked from the period of October 1992 to December 2006 [6].

The role of the Agulhas system was also underlined as a potential climate feedback mechanism trigger [7] while the influence of the El Nino Southern Oscillation (negative phase) is suggested in the recirculation region of the Agulhas Current, for instance, south of Madagascar [8]. However, the direct relationship between the synoptic and climatic events and the mesoscale ocean and atmospheric anomalies induced by Agulhas eddies is not already highlighted.

Eddies, fronts, and filaments associated with the Agulhas Current are spatially extensive and numerous with sharp horizontal sea surface temperature (SST) gradients. These discontinuities strongly impact the air-sea thermodynamics exchanges locally and regionally. A number of papers have dealt with the influence of SST fronts [9-11]; however eddies can also have large effects on the marine atmospheric boundary layer $[2,12,13]$.

During the period from 13 February 2008 to 24 March 2008, the BONUS-GoodHope cruise transected the Southern Ocean, while sampling both the physical structure of the ocean and atmosphere. During the return leg of the cruise a warm core eddy originating from the Agulhas Retroflection region was crossed and sampled with nine Expendable Bathythermograph Temperature (XBT) probes and five atmospheric radiosoundings on 21 March 2008 (Figure 1).

This paper describes a full section of a warm ocean eddy ejected by the Agulhas Retroflection by means of both 


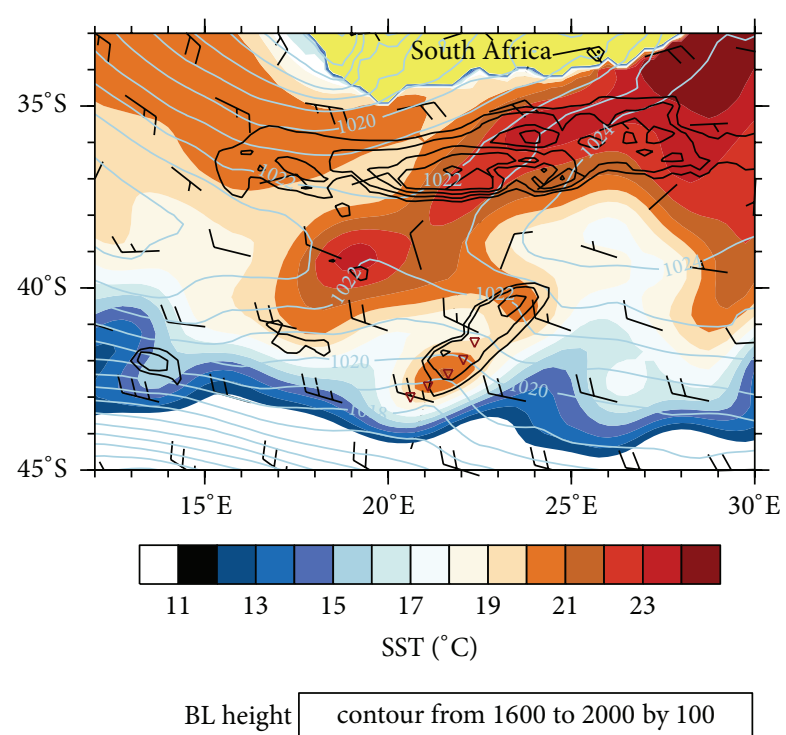

FIGURE 1: Operational ECMWF archive (forecast with a delayed cutoff) at 09H UTC, 21 March 2008. Wind barbs, pressure field with blue contours, BL height with black contours (from $1800 \mathrm{~m}$ to $2000 \mathrm{~m}$ height only), and SST as colored background. Triangles represent radiosounding releases.

ocean (surface to $\sim 800 \mathrm{~m}$ depth) and atmosphere (surface to $600 \mathrm{hPa}$ ) measurements.

\section{Data and Methods}

On 21 March, a series of nine Sippican Deep Blue XBTs were deployed across the eddy feature with an average spatial resolution of $27 \mathrm{~km}$. All XBTs reached a maximum working depth of $\sim 800 \mathrm{~m}$ with a sampling resolution of $2 \mathrm{~m}$. Fine weather conditions meant that no surface or subsurface sensor spiking was recorded during the deployments.

Over the same period, five radiosondes were released every $\sim 2$ hours with a horizontal spatial resolution between $51 \mathrm{~km}$ and $59 \mathrm{~km}$. The radiosonde sampling frequency was 1 second.

Figure 2(b) presents Maps of Absolute Dynamic Topography as well as locations of XBTs and radiosondes releases.

An ocean-atmosphere cross section is provided in Figure 3. The standard meteorological data recorded onboard the ship has been used to compute the air-sea heat fluxes using the COARE [14] algorithm and are presented in Figure 4.

Additionally, large scale and $0.25^{\circ} \times 0.25^{\circ}$ gridded products from the Operational ECMWF Archive (forecast with a delayed cutoff) provide pressure field, BL height, Convective Available Potential Energy (CAPE), and SST used in the archive.

\section{Eddy Origin and Characterization}

Analysis of AVISO Maps of Absolute Dynamic Topography (MADT) data in a series of plotted "snapshots" (Figures 2(a) and 2(c)) are used to identify the true origin and horizontal extent of the warm core anticyclonic eddy. A preexisting positive anomaly can be seen clearly merging with the southern extent of the Agulhas Retroflection and Agulhas Return Current during late February 2008 (Figure 2(a)). This merging event results in an intense southwestern extension of the Agulhas Return Current to $\sim 44^{\circ} \mathrm{S}$, towards the middle of March 2008, which spawns a warm eddy (centered at $42.5^{\circ} \mathrm{S}$; $21.5^{\circ} \mathrm{E}$ ) around 19 March 2008 (Figure 2(a)). The eddy was sampled on 21 March 2008 (Figure 2(b)), just a few days after it was observed separating from the Agulhas Return Current. Using the XBT data the eddy core was located at approximately $42.3^{\circ} \mathrm{S}$. The XBT cross section shows eddy core temperatures of $\sim 21^{\circ} \mathrm{C}$ which are $\sim 5^{\circ} \mathrm{C}$ higher than the immediate surrounding waters and emphasizes the intensity of this anomalous feature in the region. Its young age is also captured by the temperature cross section (Figure 3), which shows that the eddy has not yet undergone extensive convective overturning in the upper layers of the water column. In older eddies, this overturning can homogenize eddy core temperatures from the surface to beyond $800 \mathrm{~m}$ depth (e.g., [15]). In this case, a strong thermocline is still visible at $\sim 100 \mathrm{~m}$ overlying characteristic bowed isotherms at this depth. The temperature structure of the eddy extends beyond the maximum measured depth $(800 \mathrm{~m})$ of the XBT probes, with its subsurface core located at $42.5^{\circ} \mathrm{S}$. The eddy's axial center was offset towards the north in the upper layer where higher heat content was recorded in comparison to the deeper layers beyond $500 \mathrm{~m}$.

Following sampling on 21 March, the eddy moved southwestwards (Figure 2(c)) to the southern location of the Agulhas Retroflection before moving northeastwards where it was reabsorbed by the Agulhas Return Current around 6 August 2008. The eddy's lifespan exceeded 4 months during which the AMSR-E data exhibited a gradual decrease of the eddy SST signal likely due to heat loss at the surface and by mixing processes.

\section{Atmospheric Eddy Influences}

4.1. Synoptic Situation. Sampling over the eddy commenced to the east of a saddle point between four atmospheric systems yielding moderate to strong west to northwesterly winds (Figure 1). The four atmospheric systems exhibited on the surface pressure field included two cyclones located to the north $(1010 \mathrm{hPa})$ and the south $(978 \mathrm{hPa})$ and two anticyclones to the east $(1025 \mathrm{hPa})$ and the west $(1023 \mathrm{hPa})$. The wind over the area and during the sampling (from 04h53 to 13 h43 UTC) remained mostly westerly with minor wind direction and intensity variations.

4.2. Sea Surface Observations. Several measured and derived variables at the ocean-atmosphere interface are shown in Figure 4.

The SST curve in Figure 4 clearly marks the Agulhas Ring's southern edge where an abrupt increase of SST from $17.5^{\circ} \mathrm{C}$ to $22^{\circ} \mathrm{C}$ is observed between $43.2^{\circ} \mathrm{S}$ and $41^{\circ} \mathrm{S}$. At the northern edge of the eddy the sharp SST gradient occurs over a shorter distance, which may be explained by the close 


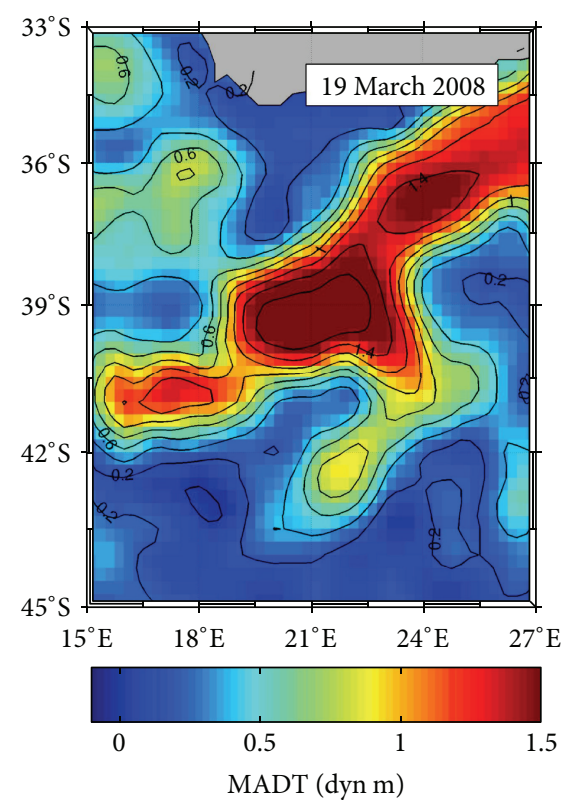

(a)

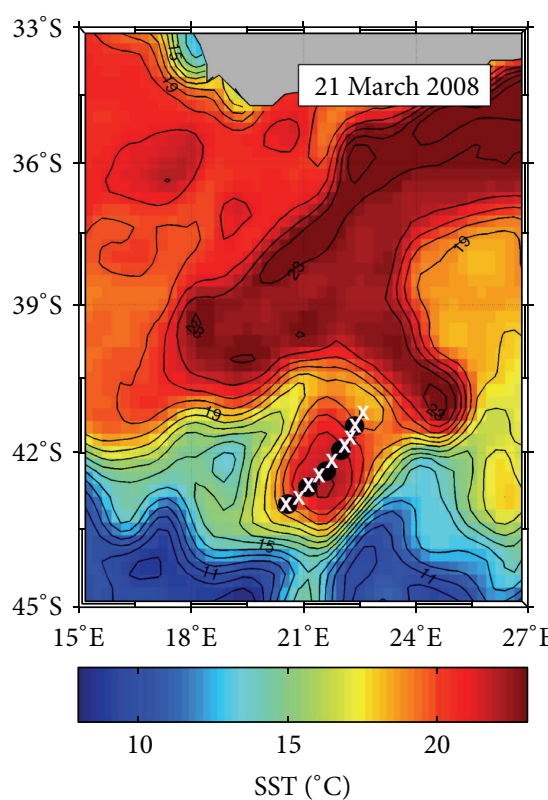

(b)

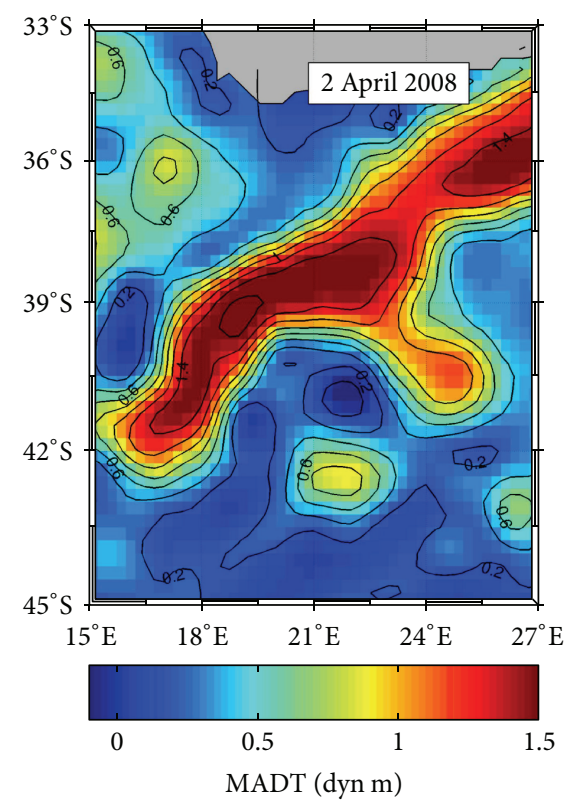

(c)

FIgure 2: Maps of Absolute Dynamic Topography (MADT), snapshot for (a) 19 March 2008 and (c) 2 April 2008. AMSR-E SST is presented for 21 March 2008 (b) with location of XBT releases (white crosses) and radiosounding releases (black circles).

proximity of the Agulhas Retroflection to the northern edge of the Agulhas Ring.

There are substantial impacts on the atmospheric latent heat flux (LHF) and sensible heat flux (SHF) by the warm eddy. A sharp LHF increase from $100 \mathrm{~W} / \mathrm{m}^{2}$ to $500 \mathrm{~W} / \mathrm{m}^{2}$ is observed in the shipborne measurements over the southern half of the eddy $\left(44.2-42.8^{\circ} \mathrm{S}\right)$. This dramatic LHF increase reveals a strong ocean-atmosphere flux immediately above the eddy, which correlates with the strongly positive observed SST anomalies (Figure 4(a)) and the enhanced heat content in the upper $200 \mathrm{~m}$ (Figure 3).

In addition, the SHF nearly doubles at the southern eddy edge progressing from approximately $45 \mathrm{~W} / \mathrm{m}^{2}$ to $85 \mathrm{~W} / \mathrm{m}^{2}$ over the same latitudinal range but gradually decreases towards the northern edge of the eddy, located at $41.2^{\circ} \mathrm{S}$, beyond which both the SHF and the LHF abruptly decrease. The gradual northward decrease of the SHF can be explained by the decrease of the south to north air-sea temperature gradient where the air temperature increases from $12^{\circ} \mathrm{C}$ at $43^{\circ} \mathrm{S}$ to $17^{\circ} \mathrm{C}$ at $41^{\circ} \mathrm{S}$.

The net heat budget (NHB) presented in Figure 4(c) reaffirms the oceanic heat loss from $44^{\circ} \mathrm{S}$ to $42.5^{\circ} \mathrm{S}$ over the eddy related to the combination of the high SHF and LHF magnitudes (combined as the turbulent heat fluxes in Figure 4(b)). The turbulent heat fluxes are thus responsible for a high level of energy loss by the eddy and are only counterbalanced when incoming solar radiation reaches a maximum between $11 \mathrm{~h} 00$ and $13 \mathrm{~h} 00$ UTC. However, even during this period, the energy gain by the ocean is low compared with amount lost during the hours preceding and following this time. This clearly indicates that the eddy heat loss, during the period of observation, covers the period of highest incoming solar radiation.
Wind intensities also reveal significant increases above the eddy indicating that positive SST anomalies lead to stronger winds. In this instance, the eddy core is located in the northern part of the eddy where the strongest wind speed is observed $(\sim 17 \mathrm{~m} / \mathrm{s})$. This observation has previously been noted in previous works by Rouault et al. [16] and O'Neill et al. [11]. According to White and Annis [17], the wind stress is enhanced over warm eddies when westerly winds blow.

The sampled eddy is located where no strong fluctuations in the analyzed synoptic wind stress are observed. This is related to stable synoptic conditions induced by two highpressure systems in the north and two low-pressure systems in the south of the eddy location (see Section 4.1)

Consequently, there is no synoptic explanation for the wind enhancement observed above the eddy and it is likely that only local factors are able to induce such wind stress increases. The effect of sea surface conditions inducing a thermodynamic response of the low atmosphere and/or a convective system located in the vicinity of the eddy could explain the wind enhancement. This is discussed further in Section 5.

4.3. The Atmospheric Boundary Layer. The vertical profiles of humidity mixing ratio $(r)$, virtual potential temperature $\left(\theta_{v}\right)$, and wind speed obtained from five radiosondes released above the eddy are shown in Figure 5.

The first radiosonde (Figure 5 (RS1)) was released on the southern edge of the eddy at $05 \mathrm{~h} 00$ UTC. A well-mixed BL can be seen from the surface to roughly $880 \mathrm{hPa}(1220 \mathrm{~m})$, with an entrainment layer above the $\mathrm{BL}$ extending up to $830 \mathrm{hPa}(1666 \mathrm{~m})$. The $\theta_{v}$ profile of the former layer is a classical well-mixed layer with a residual layer aloft. The magnitude and vertical constancy of the humidity mixing 

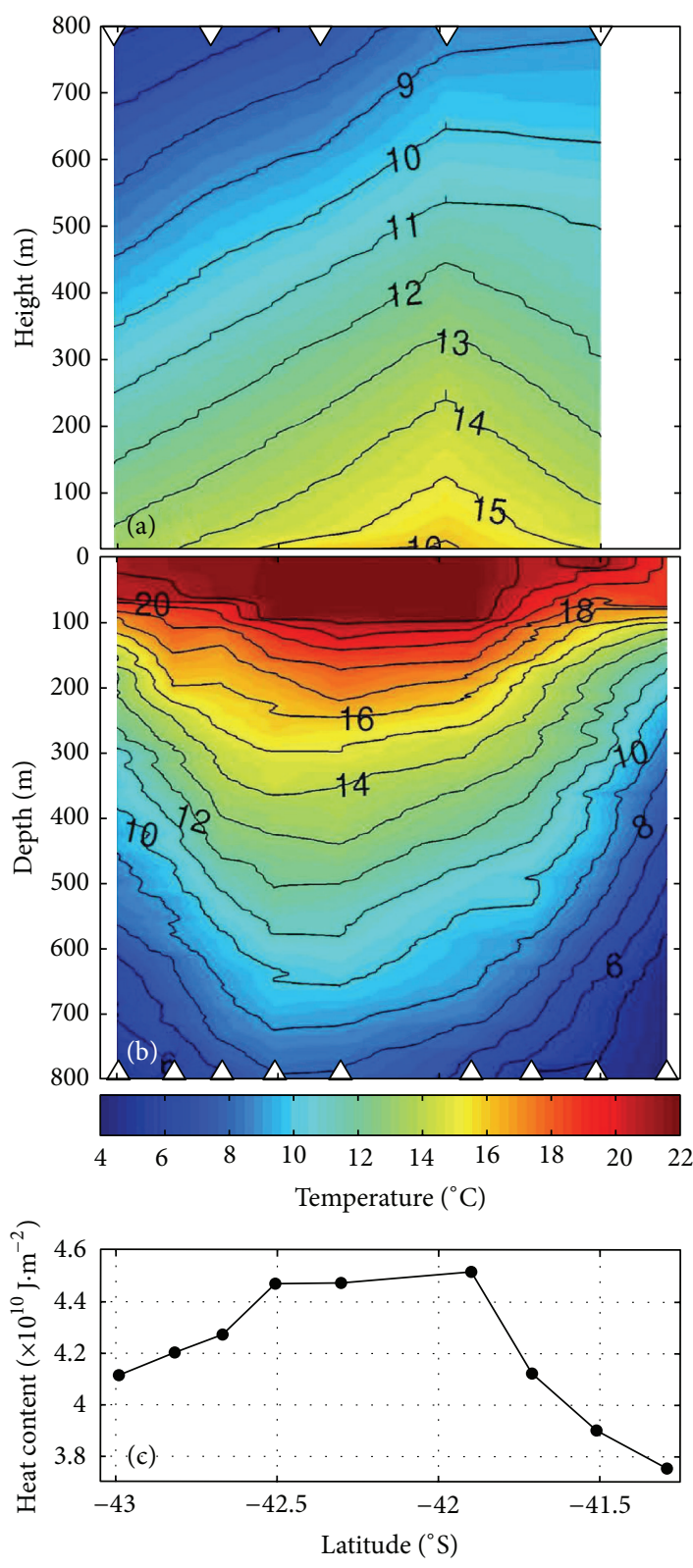

FIGURE 3: Ocean-atmosphere cross section of the warm eddy with heat content in the first $200 \mathrm{~m}$ of the ocean. (a) Atmosphere; (b) ocean. White triangles at the top are radiosounding release locations while white triangles at the bottom are XBTs release locations.

ratio indicated that the layer received energy to maintain mixing activity along the vertical extent. This mixing is clearly not driven by solar convective processes since the time of sampling occurred at 05h00 UTC when the diurnal thermal heating was at its lowest yet; it is remarkable that the $\mathrm{BL}$ is so deep. The deep vertical mixing was thus likely maintained by the THF.

Figure 3 emphasizes the asymmetric north-south eddy heat content as well as the asymmetry of the SST anomaly. The second and third radiosondes (Figure 5 (RS2) and (RS3)) were released at $07 \mathrm{~h} 00$ and $09 \mathrm{~h} 00 \mathrm{UTC}$, respectively, along the section where the SST anomaly continued to increase

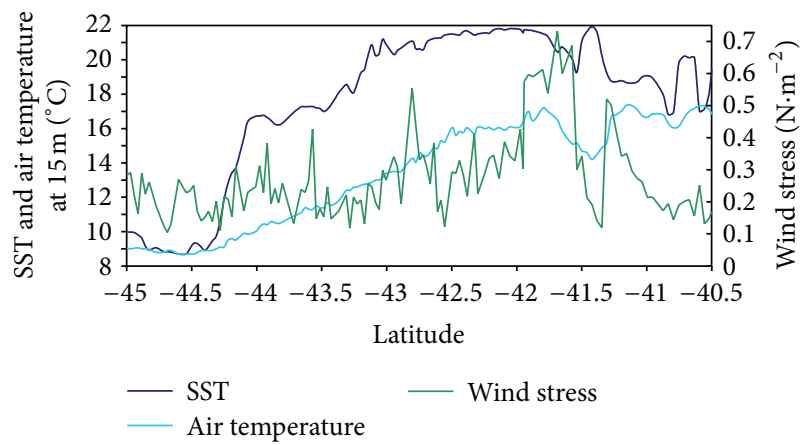

(a)

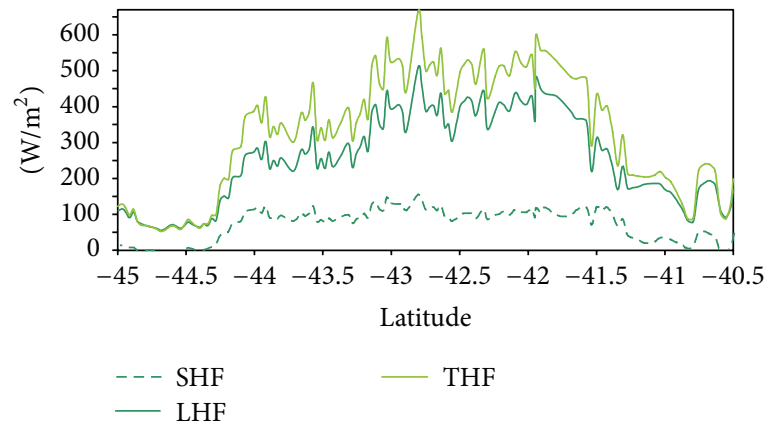

(b)

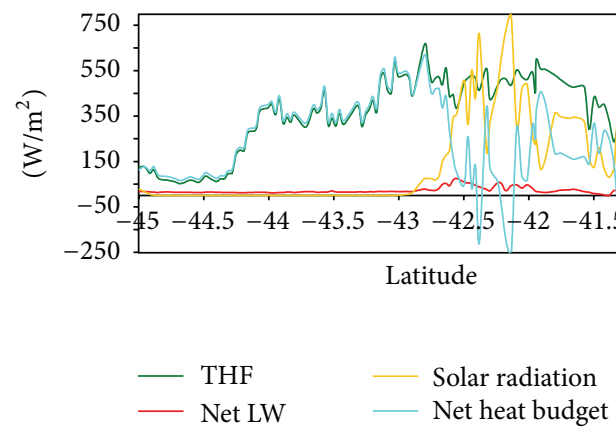

(c)

FIGURE 4: From left (south) to right (north) along the transect: measured SST, air temperature, and wind stress (a); derived sensible heat fluxes (SHF), latent heat fluxes (LHF), and turbulent heat fluxes (THF) (b); turbulent heat fluxes (THF), net longwave radiation, solar radiation, and net heat budget (c).

as the ship moved towards the warm core of the eddy. For these two radiosondes, the boundary layer split in two layers: an internal layer overridden by a residual layer representing effective but less efficient humidity mixing values along the vertical axis. If one considers the top of the $\mathrm{BL}$ as the top of the residual layer, the BL height reaches roughly $800 \mathrm{hPa}$ $(2000 \mathrm{~m})$.

The fourth radiosonde (Figure 5 (RS4)) was released in the warmer part of the eddy at 11h00 UTC where the highest surface wind speed and SHF were observed but before the rapid SHF decrease at the northern edge of the eddy. The BL at this location exhibits an internal layer with two distinct layers above it separated by $r$ and $\theta_{v}$ gap. The first distinct 
$r(\mathrm{~g} / \mathrm{kg}), \theta_{v}\left({ }^{\circ} \mathrm{C}\right)$
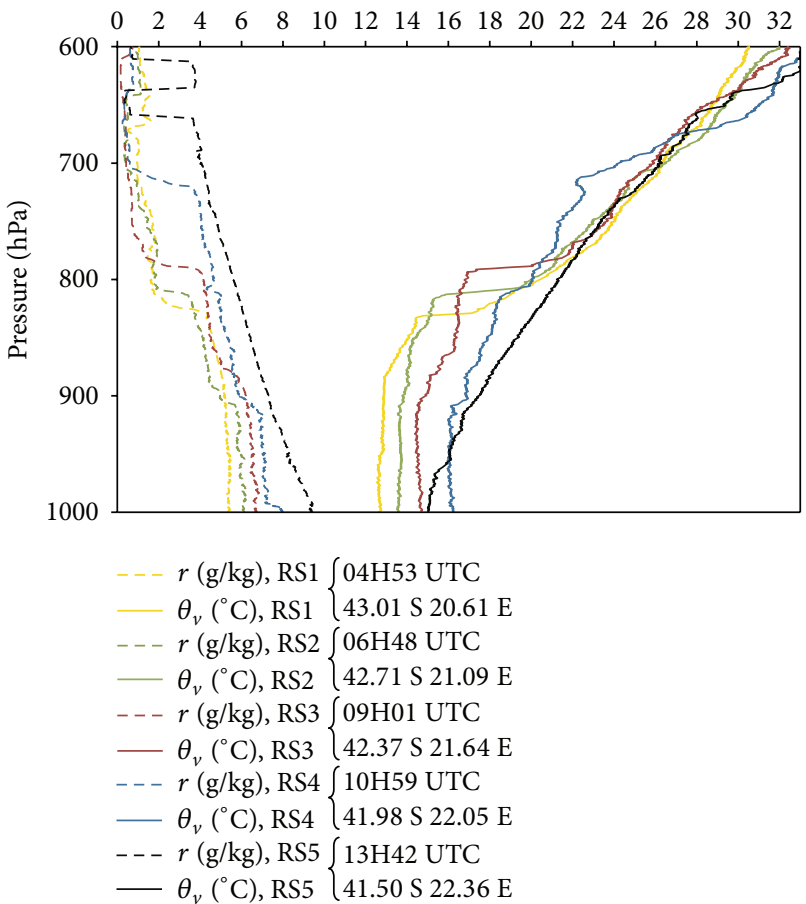

FIGURE 5: Radiosounding vertical profiles of mixing ratio and virtual temperature as well as time and location releases.

layer is located at $802 \mathrm{hPa}(1968 \mathrm{~m})$ and the second at $720 \mathrm{hPa}$ $(2800 \mathrm{~m})$.

The last radiosonde (Figure 5 (RS5)) was released over the northern eddy edge where the SST began to gradually decrease. It was located just south of a meander in the Agulhas Return Current which is represented clearly by a sharp increase in the ship observed SST near $40.8^{\circ} \mathrm{S}$ (Figures 2(b) and 3(a)). This last sounding revealed vertical $r$ and $\theta_{v}$ profiles which indicated the presence of clouds near the surface. Relative humidity vertical profiles (not shown) also confirm cloud layers from $994 \mathrm{hPa}(190 \mathrm{~m})$ up to $743 \mathrm{hPa}$ $(2500 \mathrm{~m})$ which is not particularly surprising as the Agulhas Return Current area is well known for frequent and persistent cloudiness due to the presence of a warm current flowing beneath warm and humid boundary layer air (via an important LHF from ocean surface). This intense cloud cover is confirmed by satellite imagery.

\section{Discussion and Conclusion}

It has been shown that an extensive deepening ( $>1400 \mathrm{~m})$ of the BL is observed immediately above a warm cored eddy originating from the Agulhas Current Retroflection. It is largely over the deepening previously observed in this region $[2,18]$. However, these previous studies were performed with radiosondes released with a poor time and spatial resolution and no systematic ocean sampling across eddies was performed.

The deepening of the BL is likely associated with powerful upward surface heat fluxes detected above the eddy. However, the deepening could also have been induced by either a synoptic meteorological situation or a local convective system. The lack of in situ data over the region surrounding (300 to $1000 \mathrm{~km}$ ) the eddy leads to some difficulty at determining a sole explanation with direct observations. The closest off-ship atmospheric soundings originate from Cape Town and Port Elizabeth but these sites are too far from our region of interest to draw any conclusions.

However, the ECMWF archive provides information at 09h00 and 12h00 UTC on 21 March 2008 (Figure 1). It is remarkable that the SST used in the operational ECMWF model correctly locates the warm eddy close to the Agulhas Retroflection. ECMWF archive data also reveals that the CAPE over the oceanic region bounded by $10^{\circ} \mathrm{W}$ to $30^{\circ} \mathrm{E}$ and $31^{\circ} \mathrm{S}$ to $51^{\circ} \mathrm{S}$ is very weak $\left(<100 \mathrm{~J} \cdot \mathrm{kg}^{-1}\right)$ and measures less than $40 \mathrm{~J} \cdot \mathrm{kg}^{-1}$ over the eddy region for both the $09 \mathrm{~h} 00$ and 12h00 UTC datasets (not shown). This confirms that convective activity is not responsible for the deepening of the $\mathrm{BL}$ during the early morning of 21 March. This is coherent with the low level clouds and westerly winds observed onboard the ship before and after crossing the STF. The ECMWF archive BL height presents an isolated bump where the eddy is located while another elevation is located above the meander from where the eddy was ejected. Above the eddy, the model generates the highest deepening of the $\mathrm{BL}$ up to $1680 \mathrm{~m}$, which is less than the mean observed BL depth of $2000 \mathrm{~m}$ across the eddy (as described in Section 4.3).

The joint analysis of the synoptic situation described in Section 4.1 and the ECMWF archive data indicates that the BL deepening that occurred between $06 \mathrm{~h} 00$ and 12h00 UTC was not due to a synoptic change (air mass interactions, e.g.). This confirms that the BL deepening above the eddy is likely caused by the eddy itself. The observed turbulent heat flux increases over the warm eddy enhanced the vertical turbulent mixing (see mixing ratio within the BL in Figure 4) and then deepened the BL over the eddy.

Moreover, the winds were mainly westerly and blew from an area of relatively cool to warm surface waters (Figure 1). The vertical mixing is thus maintained by the regular westerly wind, which advected colder and dryer air over the eddy. This wind advection as well as turbulent heat flux generated a vertical pressure anomaly from the surface to the upper BL that led to stronger surface winds over the eddy core where the turbulent heat fluxes were the most influential (see [19]).

Previous studies which sampled eddies over the same region $[12,18]$ described a deepening of the $\mathrm{BL}$ associated with a significant increase of turbulent heat fluxes but it is the first time that the observed deepening reached values described in this study.

This means that particularly strong positive SST anomalies associated with ocean eddies deeply impacted the atmosphere. Also, the results suggest that the eddies can influence the atmosphere rapidly, as the sampled eddy had only formed a week earlier.

The deepening of the BL occurs primarily above the eddy and seems unlikely to be connected to the vertical atmospheric structure beyond the northern part of the STF. The deepening of the atmosphere above warm fronts actually 
follows similar rules compared with the one observed over an eddy edge. Interestingly, the ECMWF archive shows that no dramatic atmospheric deepening occurs at the location of the STF compared with the deepening over the eddy.

During the austral summer of 2008, the net heat budget above the eddy was almost always negative suggesting it primarily lost its energy to the atmospheric boundary layer during the sampling period. The heat release is expected to be amplified during austral winter months when the atmospheric to ocean temperature gradient is normally greater. The evidence presented in this study shows that these events of mesoscale oceanic features seem to play a key role in the air-sea exchanges in the region. Dramatic BL deepening and the penetration of humidity at high altitudes, as observed here, allow for convective cloud formation and the rapid release of latent energy to the surrounding atmosphere. The role of such anomalies thus has an impact on storms and convective systems, which likely leads to modified rainfall over an extended region, which may include the South African coastal areas (indeed the atmospheric recirculation over the Cape Basin region associated with the eastwards displacement of low-pressure systems induces some condensation and water and energy release far from the region where the evaporation occurred).

Moreover, the increased humidity and cloud cover extensively modify the radiative energy budget over such an area.

For these reasons, such eddies must be considered as major humidity and energy sources for the medium-toupper atmosphere. Due to the longevity of these oceanic features (multiple months) and their number (roughly 49 per year, c.f. Section 1), their role in the regional meteorological processes, and the regional climate via radiative and evaporative transfers, they warrant further study. For instance, quantifying more precisely the mean atmospheric heat release by such oceanic features will be very useful in order to highlight connection with the synoptic climate and Indo-Pacific events.

\section{Conflict of Interests}

The authors declare that there is no conflict of interests regarding the publication of this paper.

\section{Acknowledgments}

The authors are thankful to all the R/V Marion DufresneIPEV crew and E. Key specially for their help in the data collection. The IPY/BONUS-GoodHope project is supported by the Institut National des Sciences de l'Univers, CNRS, IFREMER, and the Agence Nationale de la Recherche. The authors thank B. Chapron, P. Minnet, and the University of Miami for their support. Sebastian Swart was supported through a Southern Ocean Carbon and Climate Observatory postdoctoral fellowship funded by ACCESS and the NRF/SANAP.

\section{References}

[1] M. R. Jury, "A review of research on ocean-atmosphere interactions and South-African climate variability," South African Journal of Science, vol. 91, no. 6, pp. 289-294, 1995.

[2] M. Rouault and J. R. E. Lutjeharms, "Air-sea exchange over an Agulhas eddy at the subtropical convergence," The Global Atmosphere and Ocean System, vol. 7, no. 2, pp. 125-150, 2000.

[3] J. R. E. Lutjeharms, The Agulhas Current, Springer, Berlin, Germany, 2006.

[4] J. R. E. Lutjeharms and R. C. Van Ballegooyen, "The retroflection of the Agulhas current," Journal of Physical Oceanography, vol. 18, no. 11, pp. 1570-1583, 1988.

[5] O. Boebel, J. Lutjeharms, C. Schmid, W. Zenk, T. Rossby, and C. Barron, "The Cape Cauldron: a regime of turbulent interocean exchange," Deep-Sea Research Part II: Topical Studies in Oceanography, vol. 50, no. 1, pp. 57-86, 2003.

[6] G. Dencausse, M. Arhan, and S. Speich, "Routes of Agulhas rings in the southeastern Cape Basin," Deep-Sea Research I, vol. 57, pp. 1406-1421, 2010.

[7] L. M. Beal, W. P. M. De Ruijter, A. Biastoch et al., "On the role of the Agulhas system in ocean circulation and climate," Nature, vol. 472, no. 7344, pp. 429-436, 2011.

[8] W. P. M. de Ruijter, H. M. van Aken, E. J. Beier, J. R. E. Lutjeharms, R. P. Matano, and M. W. Schouten, "Eddies and dipoles around South Madagascar: formation, pathways and large-scale impact," Deep Sea Research Part I: Oceanographic Research Papers, vol. 51, no. 3, pp. 383-400, 2004.

[9] A. M. Lee-Thorp, M. Rouault, and J. R. E. Lutjeharms, "Moisture uptake in the boundary layer above the Agulhas Current: a case study," Journal of Geophysical Research: Oceans, vol. 104, no. 1, pp. 1423-1430, 1999.

[10] C. J. C. Reason, "Evidence for the influence of the Agulhas Current on regional atmospheric circulation patterns," Journal of Climate, vol. 14, no. 12, pp. 2769-2778, 2001.

[11] L. W. O’Neill, D. B. Chelton, S. K. Esbensen, and F. J. Wentz, "High-resolution satellite measurements of the atmospheric boundary layer response to SST variations along the Agulhas Return Current," Journal of Climate, vol. 18, no. 14, pp. 27062723, 2005.

[12] H. M. Van Aken, A. K. Van Veldhoven, C. Veth et al., "Observations of a young Agulhas ring, Astrid, during MARE in March 2000," Deep-Sea Research Part II: Topical Studies in Oceanography, vol. 50, no. 1, pp. 167-195, 2003.

[13] R. J. Small, S. P. deSzoeke, S. P. Xie et al., "Air-sea interaction over ocean fronts and eddies," Dynamics of Atmospheres and Oceans, vol. 45, no. 3-4, pp. 274-319, 2008.

[14] C. W. Fairall, E. F. Bradley, J. E. Hare, A. A. Grachev, and J. B. Edson, "Bulk parameterization of air-sea fluxes: updates and verification for the COARE algorithm," Journal of Climate, vol. 16, no. 4, pp. 571-591, 2003.

[15] M. Arhan, S. Speich, C. Messager, G. Dencausse, R. Fine, and M. Boye, "Anticyclonic and cyclonic eddies of subtropical origin in the subantarctic zone south of Africa," Journal of Geophysical Research: Oceans, vol. 116, no. 11, Article ID C11004, 2011.

[16] M. Rouault, A. M. Lee-Thorp, J. R. E. Lutjeharms, and M. Rouault, "Observations of the atmospheric boundary layer above the Agulhas current during along-current winds," Journal of Physical Oceanography, vol. 30, pp. 70-85, 2000. 
[17] W. B. White and J. L. Annis, "Coupling of extratropical mesoscale eddies in the ocean to westerly winds in the atmospheric boundary layer," Journal of Physical Oceanography, vol. 33, no. 5, pp. 1095-1107, 2003.

[18] M. Rouault and A. M. Lee-Thorp, "Fine-time resolution measurements of atmospheric boundary layer properties between Cape Town and Marion Island," South African Journal of Marine Science, vol. 17, pp. 281-296, 1996.

[19] Q. Song, P. Cornillon, and T. Hara, "Surface wind response to oceanic fronts," Journal of Geophysical Research: Oceans, vol. 111, no. 12, Article ID C12006, 2006. 

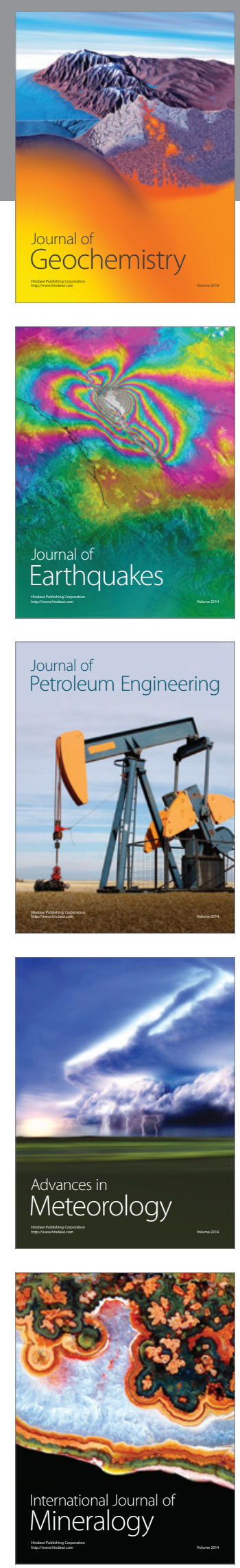
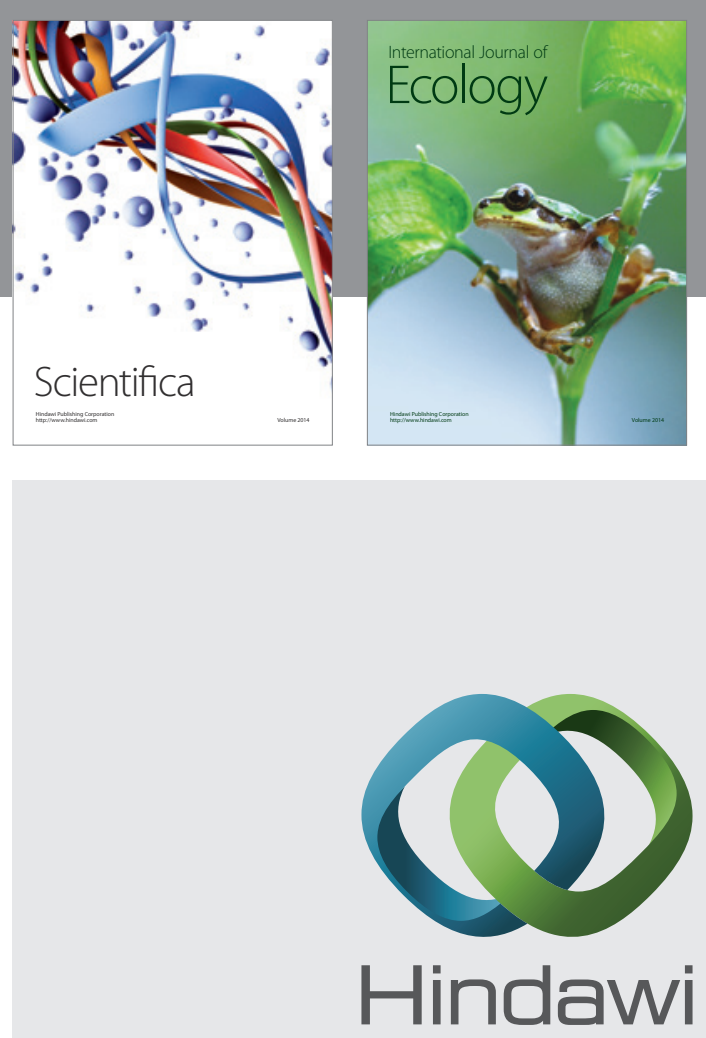

Submit your manuscripts at

http://www.hindawi.com
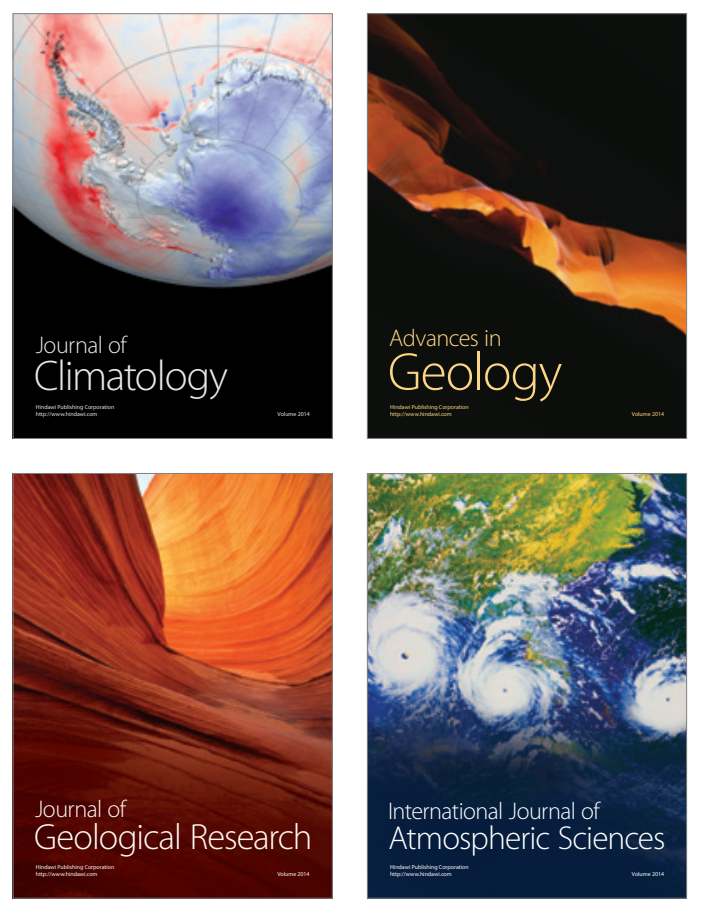

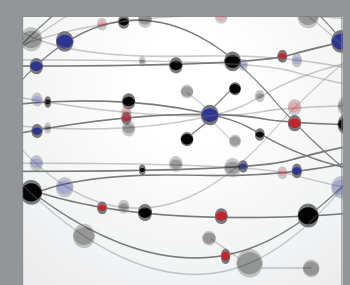

The Scientific

\section{World Journal}
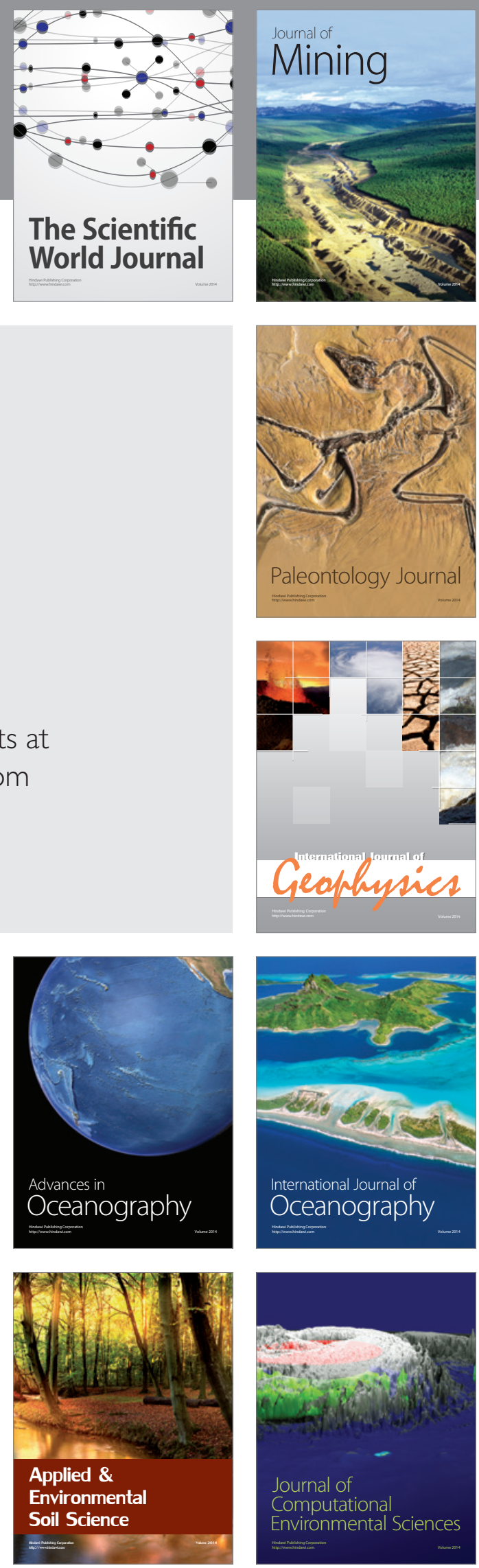